\title{
Mancha-alvo em mogno-africano no Brasil
}

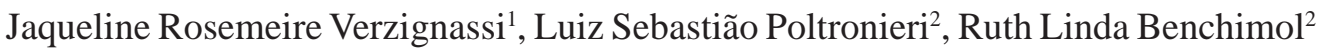

'Embrapa Gado de Corte, Rodovia BR 262, km 4, Caixa Postal 154, CEP 79002-970, Campo Grande, MS. jaqueline@cnpgc.embrapa.br

${ }^{2}$ Embrapa Amazônia Oriental, Tv. Enéas Pinheiro, S/N, CEP 66095-100, Belém, PA.

Autor para correspondência: Jaqueline R. Verzignassi

Data de chegada: 29/03/2008. Aceito para publicação em: 23/09/2008

O mogno-africano (Khaya ivorensis A. Chev.), originário da costa ocidental africana, é uma espécie florestal de grande importância para a região amazônica, não apenas pelo seu alto valor no comércio internacional, mas também pelos aspectos relativos ao rápido crescimento e pela sua resistência a algumas pragas que comumente atacam o mogno-brasileiro (Swietenia macrophylla King), como é o caso da broca da ponteira (Hypsypila grandella). Plantas de mognoafricano, de 12 meses de idade, produzidas em área de cultivo em Dom Eliseu (PA), apresentaram lesões foliares circulares a irregulares (1 a 8 mm de diâmetro), circundadas por halo de coloração púrpura e em ambas as faces do limbo foliar. Os centros das lesões apresentavam coloração clara (branco) e, com o aumento do número de lesões, constatou-se o coalescimento, originando lesões maiores. Estas lesões se tornavam escuras e atingiam grande parte do limbo foliar, ocasionando o rompimento, o secamento e a queda das folhas (Figuras 1 a 3). O material com sintomas foi coletado e encaminhado ao Laboratório de Fitopatologia da Embrapa Amazônia Oriental para análise. Procedeuse os isolamentos direto (diretamente das lesões) e indireto em meio de cultura BDA (batata-dextrose-ágar), e a identificação do microrganismo isolado de acordo com literatura pertinente. Dos isolados obtidos, efetuou-se a multiplicação do inóculo em meio BDA e, cinco dias após, procedeu-se a inoculação de discos de cultura em plantas sadias de mogno-africano. Para tanto, as folhas das plantas foram submetidas à assepsia (hipoclorito de sódio, 2\%, 2 minutos), seguida de ferimentos com agulha desinfestada em chama. Os discos de cultura foram colocados sobre os pontos feridos das folhas e as plantas permaneceram em câmara úmida por 72 horas (fotoperíodo de 12 horas de luz fluorescente contínua e 12 horas de escuro). Dos isolamentos direto e indireto, foram obtidas colônias de coloração cinza escuro, com conidióforos e conídios característicos do fungo Corynespora cassiicola (Ellis, M.B. Dematiaceous hyphomycetes. Kew: Commonwealth Mycological Institute, 1971. 608p.) (Figuras 4 e 5).

Setenta e duas horas após a inoculação, os sintomas da doença foram reproduzidos (Figuras 6 e 7). Da região da interface da lesão com o tecido sadio, reisolou-se $C$. cassiicola, comprovando a relação de patogenicidade dos isolados obtidos com o mogno-africano. O fungo C. cassicola, comum em regiões tropicais e subtropicais, é agente causal de doença foliar (mancha-alvo ou mancha-de-corinespora) em várias culturas agronômicas e florestais importantes, acometendo 16 espécies de leguminosas e mais de 50 famílias de plantas. No Pará, por exemplo, acomete alface em hidroponia, juta, cacaueiro, tomateiro, hortência, pimenteira longa, aceroleira e mamoeiro. Em seringueira, foi registrado pela primeira vez no Brasil, em 1984, em Manaus e, após, em outras localidades do Brasil e em países como a Índia, Nigéria e Malásia. Em cultivo protegido sob estufas plásticas, o patógeno foi diagnosticado como agente causal de epidemias de manchas foliares

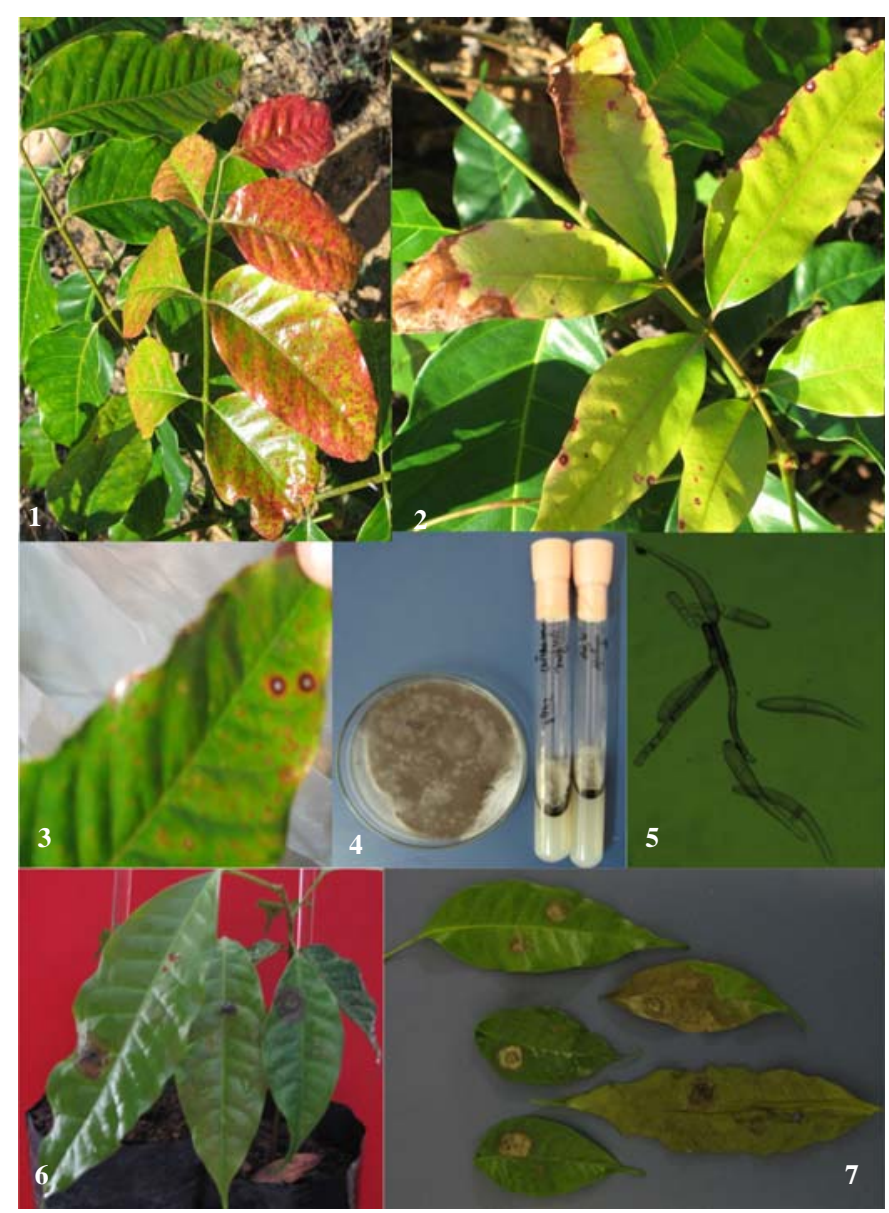

Figuras 1 a 7 - 1 a 3: Mancha-alvo em plantas de mogno-africano (Khaya ivor), causada por Corynespora cassiicola; 4: colônias do fungo em meio de BDA em placa de Petri e tubo de ensaio; 5: conidióforos e conídios do fungo (microscópio óptico, 200x); 6 e 7: lesões resultantes da inoculação artificial de plantas de mogno-africano (Fotos: Jaqueline R. Verzignassi).

em pepino tipo “japonês” no Noroeste do Estado do Paraná, com prejuízos significativos. Para a soja, única cultura agrícola para a qual existem produtos registrados no Ministério da Agricultura, Pecuária e Abastecimento para o controle da doença, são recomendados os fungicidas piraclostrobina (estrobirulina), carbendazim (benzimidazol) e epoxiconazol (triazol) + piraclostrobina (estrobirulina), todos em aplicações quinzenais. Em tomate, pulverizações com calda bordalesa têm proporcionado bons resultados no controle da doença. Alguns produtores do Paraná têm utilizado tebuconazole e carbendazin, aplicados de forma alternada e com intervalo de 15 dias entre aplicações, 
com relatos de resultados satisfatórios no controle da manha-alvo, em cucurbitáceas sob cultivo protegido, quando em início de infecção. Assim, conforme descrito, não existem produtos recomendados e registrados para o controle da doença em outras culturas além da soja. $\mathrm{O}$ fungo pode sobreviver nas folhas velhas remanescentes na planta ou nas folhas caídas no chão e também podem sobreviver em qualquer outra planta das diversas espécies hospedeiras. Os conídios são disseminados, principalmente, pelo vento e, também, pelos respingos da água da chuva. Períodos chuvosos prolongados, umidade relativa elevada e temperaturas amenas, com ótimo para a infecção a $25^{\circ} \mathrm{C}$, são condições que favorecem o desenvolvimento da doença. Como não existem produtos fungicidas registrados e recomendados para o controle da doença, algumas estratégias de controle de caráter cultural, bem como tentativa de controle com produtos alternativos nos viveiros, devem ser empregadas. Deve- se utilizar mudas sadias e efetuar inspeções periódicas em viveiros, jardins clonais e culturas recém implantadas, eliminando-se folhas com sintomas, assim como as folhas velhas caídas no chão, para reduzir a pressão de inóculo do patógeno. Em algumas espécies agrícolas nas quais a mancha-alvo apresenta relativa importância econômica, como soja e tomateiro, existem estudos com vistas à busca por material resistente por meio do melhoramento genético. Em levantamentos anteriores de doenças efetuados em áreas plantadas com o mogno-africano no Pará, foram encontrados Thanatephorus cucumeris, Cercospora sp., Pellicularia koleroga, Sclerotium coffeicola, Cylindrocladium parasiticum e Rigidoporus lignosus, causando mancha areolada, mancha parda, queima-do-fio, mancha zonada, mancha foliar e podridão branca, respectivamente. Este é o primeiro relato de Corynespora cassiicola como agente etiológico da mancha-alvo em mogno-africano no Brasil. 